\title{
The orientation reaction as a mediator of sensory preconditioning'
}

\section{E. R. PARKS, DEPARTMENT OF PSYCHOLOGY, WABASH COLLEGE, Crawfordsville, Indiana}

It was hypothesized that the orientation reaction mediates sensory preconditioning. The test of the hypothesis consisted of habituating the orientation reaction to the two stimuli used in sensory preconditioning in one group of rats and comparing their performance to a group whose orientation reactions were not habituated. The results clearly indicate that repeated exposure to two stimuli hinders the development of a learned association between them when they are subsequently paired and, thus, support the hypothesis.

Operationally, sensory preconditioning (SPC) consists of repeatedly presenting an organism with a pair of stimuli (A and $B$ ); and later determining whether the organism has learned to associate $\mathbf{A}$ and $\mathbf{B}$ by conditioning a response to $B$ and testing whether the response is also elicited by $A$. SPC is a procedure which produces an apparent learned association between two stimuli rather than between a stimulus and a response and thus does not readily fit either the S-R instrumental or classical conditioning paradigms. Nevertheless, many investigators (see Seidel, 1958) have tried to show that SPC is a special case of classical conditioning. They have done this largely by assuming that some covert response mediates the learned association between the two stimuli and then testing to see whether the association is formed according to the rules of classical conditioning.

The present experiment is a test of an S-R interpretation of sensory preconditioning; it differs from previous studies by specifying the response believed to mediate the learned association between the two stimuli. The response hypothesized in the present experiment to mediate SPC is the orientation reaction (OR). This reaction is an ideal candidate for the response mediating SPC because: (a) it occurs to any stimulus change, including the stimuli used in SPC; and (b) it consists of a number of components which conceivably could supply the afferent feedback necessary for a mediating response. For example, included among the components of the OR are dilating of the forehead and constricting of the extremity blood vessels, decreased heart rate, pupillary dilation, turning of the head and eyes toward the source of stimulation, and, in animals so predisposed, ear perking and sniffing, (see Berlyne, 1960 or Razran, 1961).

The hypothesis that the OR mediates SPC is supported by the following studies. Parks (1963) found that chlorpromazine, a tranquilizer that blocks the OR (Gliedman \& Gantt, 1956 and French, 1960), retards the development of SPC. Davis, Buckwald, \& Frankmann (1955) report the components of the OR have latencies of from 4-20 sec, and Hoffeld, Thompson, \& Brogden (1958) report the optimum interval between stimuli in SPC pairings to be $4 \mathrm{sec}$ or longer. Wokoun (1959) found that SPC varies inversely with the intensity of the first presented stimulus, which supports the present hypothesis since Razran (1961) reports the OR is stronger to a stimulus of low intensity than to one of high intensity. And, Thompson \& Kramer (1965) found that bilateral removal of the association areas in the cat blocks SPC. They interpret these results, together with some of their earlier work, as indicating the involvement of the OR in SPC.

The present experiment was an attempt to determine whether repeated preexposure to the SPC stimuli (habituation of the OR) prior to stimulus pairing retards the development of SPC.

Subjects. The Ss consisted of 30 male albino Holtzman rats approximately 100 days old.

Apparatus. The apparatus consisted of an enclosure within which a light and tone were presented, and a separate device for conditioning a response to test for SPC. The SPC stimuli consisted of a dim $12 \mathrm{~V}$ incandescent light (Sylvania 12ESB) and an $800 \mathrm{cps}$ tone produced by an audio generator driving a $4 \mathrm{ohm}$ speaker without amplification. The intensity of these stimuli were such that they produced the observable components of the OR (ear perking and sniffing) and a decreased heart rate, but not a startle response (crouching). The stimuli were presented to the animals in a wooden open top enclosure $9 \times 12 \times 24 \mathrm{in}$. high which was placed in a modified refrigerator.

Running in a modified Brogden-Culler (1936) wheel was used to test for SPC. The wheel was constructed of two wooden circles mounted about 4 in. apart on an axle which was parallel with the ground. Three-eighths inch brass rods inserted in holes $3 / 4 \mathrm{in}$. apart around the circumference of the wooden circles served to create an enclosure within which the rat could be placed. If the rat ran or walked within this enclosed wheel, the wheel turned. The brass rods were connected to brushes on the outside of the wheel; the brushes were connected to a shock scrambler through which $.5 \mathrm{~mA}$ of constant current could be applied to the feet of the animal. Running by the rat was counted by means of a photo-electric relay mounted and wired such that the relay points would close whenever the wheel turned approximately $18 \mathrm{deg}$. The conditioning stimuli were the same as those used for initial pairing; the bulb and speaker were mounted on the axle within the wheel. The light, tone, and avoidance trial presentations were controlled by logical module programming units. Responses were recorded on a print-out counter.

Procedure. The 30 rats were randomly divided into three groups of 10 each: a control group, a standard SPC group, and a habituation group. Each control animal was placed in the stimulus presentation box and left for approximately $1 \mathrm{~h}$ with no stimulus presentations given. It was then removed and placed in the wheel. In the wheel the animal was presented with the tone for $6 \mathrm{sec}$, then tone and shock until it ran enough to move the wheel from 36 to $54 \mathrm{deg}$, i.e., caused the photo-electric relay to close three times. If the animal ran enough to close the relay three times after tone onset but before shock onset, the tone was terminated and shock was not presented. In order to distinguish between running in general and running to the tone the animal was said to have avoided shock only if it ran enough to prevent being shocked and in addition ran more during the $6 \mathrm{sec}$ period following tone onset than it did during the $6 \mathrm{sec}$ period immediately preceding tone onset. For example, if the rat caused the relay to close nine times during the $6 \mathrm{sec}$ prior to tone onset and eight or nine times during the $6 \mathrm{sec}$ after tone onset it was not said to have shown an avoidance response even though it did in fact keep from being shocked. On the other hand, if it closed the relay nine times before and 10 times after tone onset it was said to have avoided. Trials were given every minute until the rat had avoided shock eight out of 10 trials. Immediately after reaching the avoidance criterion to the tone, the animal was retrained to avoid shock to the light using the same procedure and criterion outlined above for the tone.

The standard SPC group animals were placed in the stimulus presentation box and presented with a $6 \mathrm{sec}$ light followed immediately by a $6 \mathrm{sec}$ tone. These stimulus pairs were presented every minute for 30 presentations. Following these stimulus presentations the animals were placed in the wheel and put through the same training procedure as were the control arimals.

The habituation group animals were placed in the stimulus presentation box and presented a $6 \mathrm{sec}$ light followed in $1 \mathrm{~min}$ with a $6 \mathrm{sec}$ tone. These stimuli were presented every minute until each had been presented 60 times. Following this habituation procedure the habituation animals were treated as SPC animals.

Results. Table 1 shows the mean number of trials to criterion to both the light and tone for the three groups. A Kruskal-Wallis one-way analysis of variance on the trials to criterion to the tone yields an $\mathrm{H}=.58$ which is associated with a probability of approximately .25 . Thus, there appears to be no significant difference between the groups in initial learning.

The measure of degree of SPC was the percentage difference in trials to avoidance criterion between learning to the tone and learning to the light. The percentage changes for each group are also shown in Table 1. A Kruskal-Wallis one-way analysis of variance indicates there is a difference, $p=.001$, in the degree of SPC among the three groups. The comparison of most importance for the hypothesis is that between the standard SPC and habituation groups. A Mann-Whitney $U$ shows there is a difference, $p=.022$, in the amount of SPC between these two groups, 
Table 1

Mean Trials to Criterion and SPC Scores

\begin{tabular}{lccc} 
& \multicolumn{3}{c}{ Treatments } \\
\cline { 2 - 4 } Item & Standard SPC & Habituation & Control \\
\hline $\begin{array}{l}\text { Trials to } \\
\text { tone avoidance }\end{array}$ & 61 & 42 & 44 \\
$\begin{array}{l}\text { Trials to } \\
\text { light avoidance }\end{array}$ & 25 & 30 & 80 \\
$\begin{array}{l}\text { Percentage change: } \\
\text { tone to light }\end{array}$ & 49 & 21 & -100 \\
\hline
\end{tabular}

with the SPC group showing more SPC than the habituation group. There is obviously a difference between the control group and the habituation-SPC groups combined. This was tested for significance using a Mann-Whitney $\mathrm{U}$ which yields a $\mathrm{p}=.001$.

Conclusion. Repeated exposure to two stimuli prior to pairing is seen by the results of this experiment to hinder the learning of an association between them when they are subsequently paired. One possible explanation for these results is that the OR has components which produce afferent feedback which in turn mediates the learned association between the two paired stimuli. And, that when the OR has been habituated to the two stimuli prior to pairings, the amount of afferent feedback is reduced, thus reducing the strength of the association established between the two stimuli.

of importance to the interpretation of the present data are the studies which show that repeated preexposure to a stimulus will weaken the effectiveness of that stimulus as a CS in later conditioning, a phenomenon known as latent inhibition. Lubow (1965), found, for example, that repeated exposure to a stimulus which was later used as a CS in classically conditioning a leg flexion response decreased the effectiveness of that stimulus as CS. In our laboratory, Ackil also found this to be true for a CS used in avoidance learning in the wheel used in the present experiment. It is possible the weakened SPC resulting from preexposing the animals to the SPC stimuli before stimulus pairings in the present experiment is another example of latent inhibition. But it should be noted that latent inhibition is an empirical rather than a theoretical term and as such is a label and not an explanation. When an explanation of latent inhibition is advanced it may serve as well for an explanation of the results of the present experiment. On the other hand, the explanation given for the present experiment, i.e., that SPC is mediated by the OR, may serve as well for an explanation of the results of latent inhibition, i.e., that leg flexion and avoidance learning is mediated by the $O R$.

\section{REFERENCES}

BERLYNE, D. E. Conflict, arousal and curiosity. New York: McGraw Hill, 1960.

BRODGEN, W. J., \& CULLER, E. Device for the motor conditioning of small animals. Science, 1936, 83, 269-270.

DAVIS, R. C., BUCHWALD, A. M., \& FRANKMANN, R. W. Autonomic and muscular responses, and their relation to simple stimuli. Psychol. mono., 1955, Vol. 69, No. 20.

FRENCH, J. D. The reticular formation, In J. Field, H. W. Magoun, \& V. E. Hall, (Eds.), Handbook of physiology, section 1: Neurophysiology. Vol. II, Washington, D. C.: American Physiol. Society, 1960.

GLIEDMAN, L. H., \& GANTT, W. H. The effects of reserpine and chlorpromazine on orienting behavior and retention of conditioned reflexes. South. Med. J., 1956, 49,880-889.

HOFFELD, D. R., THOMPSON, R. F., \& BRODGEN, W. J. Effect of stimuli time relations during preconditioning training upon the magnitude of sensory preconditioning. J. exp. Psychol., 1958, 56, 437-442.

LUBOW, R., \& MOORE, A. Latent inhibition: the effect of nonreinforced pre-exposure to the conditioning stimulus. J. comp. physiol. Psychol., $1959,52,415-419$.

PARKS, E. R. The orientation reaction as a mediator in sensory preconditioning. Unpublished doctoral dissertation, University of Nebraska, 1963.

RAZRAN, G. The observable unconscious and the inferable conscious in current Soviet psychophysiology: interoceptive conditioning, semantic conditioning, and the orienting reflex. Psychol. Rev., 1961, 68, No. 2.

SEIDEL, R. J. An investigation of the mediation process in preconditioning. J. exp. Psychol., 1958, 56, 220-225.

THOMPSON, R. F , \& KRAMER, R. F. Role of association cortex in sensory preconditioning. J. comp. physiol. Psychol., 1965, 60, 186-191.

WOKOUN, F. W. The effect of stimulus intensity in sensory preconditioning. Unpublished doctoral dissertation, University of Nebraska, 1959.

NOTE

1. This research was supported by NIMH Grant MH12345-02. 